\title{
Musicologia no século XX: Os discursos modernistas de Theodor Adorno e Mário de Andrade
}

\author{
Musicology on the 20th century: The modernist \\ discourses of Theodor Adorno and Mário de Andrade
}




\section{DAPesquisa}

\section{Resumo}

Vinte anos separam a publicação do "Ensaio sobre a música brasileira" (1921), de Mário de Andrade, e o texto "Sobre música popular" (1941), de Theodor Adorno, textos que se conectam em pelo menos um ponto: seu modernismo latente. Por meio de uma análise metodológica dessas publicações, o presente trabalho busca relacionar o pensamento dos dois autores numa perspectiva de pesquisa em músi$\mathrm{ca}$, considerando suas particularidades contextuais e alinhando-os com a grande narrativa modernista, tal como definida por Beard e Gloag (2005). Paulo Castagna fornece três parâmetros fundamentais de pesquisa que nos servem de pilares para a investigação: a norma, a técnica e o método. Ao identificar cada um desses parâmetros nos textos de Mário e de Adorno, trazemos à tona as concepções de música popular que delineiam suas abordagens musicológicas, aproximando-os epistemologicamente e demonstrando assim como seus discursos apresentam características totalizadoras que refletem a ideologia modernista e situam-nos como intelectuais do século XX.

Palavras-Chave: Musicologia; modernismo; metodologia científica; música popular.
Musicologia no século XX: Os discursos modernistas de Theodor Adorno e Mário de Andrade

\section{Abstract}

Twenty years separate the publication of the "Ensaio sobre a música brasileira" (1921), Mário de Andrade, and the text "On popular music" (1941), Theodor Adorno, two texts that can be connected in at least one point: their latent modernism. Through a methodological analysis of such texts, this work seeks to relate the thought of the two authors in the perspective of music research, taking into account their contextual particularities and aligning their discourse with the modernist master narrative, as defined by Beard and Gloag (2005). Paulo Castagna provides three fundamental parameters for a research method that serve us as pillars for the current investigation: the norm, the technique and the method. By identifying each of these parameters in the writings of Mário and Adorno, we point out the concepts of popular music that outline their musicological approaches, relating them epistemologically and thus demonstrating how their discourses present totalizing precepts that reflect the modernist ideology and locate them as intellectuals of the 20th century.

Keywords: Musicology; modernism; research methodology; popular music.

ISSN: 1808-3129 


\section{Introdução}

Theodor Adorno e Mário de Andrade foram, cada um à sua maneira, grandes contribuidores para o pensamento estético de seu tempo. Autores de obras que englobam amplas áreas do saber, ambos tiveram nas manifestações musicais seu grande objeto de pesquisa, que abordaram levando em conta pressupostos alinhados com o que hoje se entende por "nova musicologia", em que a sociedade, sua estrutura e suas relações estão profundamente conectadas com o modo de produzir e receber (ou consumir) música. Esta aproximação epistemológica, somada à proximidade de publicação de seus textos - 20 anos separam a publicação do "Ensaio sobre a música popular brasileira" (1921), de Mário, e o texto "Sobre música popular" (1941), de Adorno - os coloca como contemporâneos um do outro e, como não poderia deixar de ser, com similaridades e distanciamentos em seus projetos estéticos que convergem precisamente em um ponto chave: seu modernismo latente.

Este trabalho busca explorar os pontos de contato entre a musicologia de Mário de Andrade e a de Theodor Adorno, partindo da premissa de que ambos possuíam um projeto essencialmente modernista ainda que seus procedimentos fossem diferenciados. Para proceder tal investigação, será feita uma análise dos discursos dos dois intelectuais procurando identificar quais são as normas, técnicas e métodos que eles adotaram em sua produção, já que é justamente a partir da diretriz de pesquisa que se estrutura o discurso do pesquisador. Paulo Castagna nos fornece definições:

\footnotetext{
Normas são convenções, utilizadas para poupar o tempo dos leitores e para garantir modelos próximos de organização para os trabalhos científicos, variando de lugar para lugar, de época para época e, muitas vezes, de pesquisador para pesquisador. Técnicas, por outro lado, são os meios práticos para se realizar uma determinada pesquisa, para se recolher, organizar e interpretar o material que interessa ao tema e que, obviamente, dependem do método que será empregado. Métodos, no entanto, são as grandes concepções de trabalho do pesquisador, refletindo sua ideologia a respeito do significado das obras de arte no passado e no presente e do significado da própria pesquisa para a sua compreensão, dependendo de ideologias dominantes em sua época e de uma opção pessoal do próprio pesquisador. (CASTAGNA, 2008, p. 9)
}

Assim, a partir do discurso apresentado por Mário no "Ensaio sobre a música popular brasileira" e por Adorno no texto "Sobre música popular", procuraremos identificar as normas, técnicas e métodos empregados pelos autores em suas pesquisas musicológicas para trazer à tona a ideologia que habita seus posicionamentos, conectando-a posteriormente ao projeto estético que predominou no pensamento ocidental da primeira metade do século XX, o Modernismo.

\section{Mário, Adorno e suas pesquisas musicológicas}

Mário de Andrade e Adorno se debruçaram sobre a questão da música popular com intenções diferentes, e seus posicionamentos dialogam estreitamente com o contexto sócio-econômico em que cada um produziu. Mário de Andrade, já no início do século XX, atuava como escritor e intelectual no Brasil e estava muito preocupado 
com a identificação e consolidação de uma identidade nacional para o povo brasileiro. Seu interesse pela música popular, então, é despertado com o intuito de encontrar fontes culturais no território brasileiro que possam servir de inspiração e de subsídio para fundamentar as obras de seus contemporâneos, artistas e compositores. Assim, Mário vai para campo investigar as manifestações populares que encontra pelas ruas, registrando-as primeiro na forma de transcrições, posteriormente na forma de gravações com o fonógrafo, e analisa-as com a intenção de fornecer diretrizes para a produção musical e artística de seu tempo.

Adorno, por sua vez, aponta para o potencial alienante da música popular no contexto de explosão da indústria fonográfica nos Estados Unidos. Sua concepção de música popular é distinta daquela de Mário, pois não é entendida como a música das ruas, do povo, mas sim como aquela produzida em série e transformada em produto pela ação capitalista norte-americana. Sua preocupação é, então, a de apontar para a objetificação mercantilista e buscar possíveis formas de resistência a essa objetificação por meio da produção de "música artística", "séria".

Tanto a concepção de música popular presente em suas pesquisas, quanto a intencionalidade apresentada em seus discursos, que em nenhum momento é "desinteressado", definem o caráter ético-estético das abordagens dos dois autores e permitem identificar suas ideologias e seus ideais modernistas no procedimento de pesquisa. Neste sentido, por meio dos três pilares da pesquisa elencados por Paulo Castagna, voltaremos agora o olhar para os textos dos dois intelectuais com o intuito de identificar a estrutura epistemológica que dá origem aos seus posicionamentos em relação à música popular. Ao final do artigo, procuraremos relacionar tais posicionamentos com a estética modernista de forma mais ampla para situá-los enquanto pensadores do século XX.

\subsection{Normas}

No que diz respeito às normas, por não se tratarem de textos estritamente acadêmicos e formatados, o modo como cada autor estrutura e compõe seus argumentos está mais ligado a um estilo pessoal desenvolvido ao longo da obra do que a uma norma propriamente dita. $O$ texto de Adorno tem a forma e a retórica de um tratado filosófico, em que logo de início é estabelecido um recorte metodológico para que se proceda a argumentação: será analisada a "real função da música popular atual [...], o próprio fenômeno tal como ele se dá hoje." (ADORNO, 1986, p. 115) Pode-se notar o caráter cientificista de tal afirmação, que concebe um objeto claramente delimitado e coloca o discurso a serviço de uma 'real função' que será demonstrada enquanto verdade. Ainda que tal conceito de música popular refira-se mais especificamente à lógica de produção da indústria fonográfica norte-americana, com a qual Adorno se deparou ao se estabelecer nos Estados Unidos fugindo da guerra na Europa, em uma leitura crítica percebe-se na citação acima um pressuposto teórico totalizador que não pode escapar ao reducionismo e a um certo "centrismo". Voltaremos a este ponto mais adiante.

O ensaio de Mário de Andrade, por sua vez, apresenta um texto claramente influenciado pelas vertentes ficcionista e jornalística do nosso intelectual, em que há 
um flerte com a linguagem coloquial e emprego frequente de figuras de linguagem. De certa forma, sua atuação como jornalista, homem oficial (Diretor do Departamento de Cultura da Prefeitura de SP) e pesquisador de campo o aproximaram da cultura popular da sociedade da época, fazendo da sua atividade distinta daquela dos ditos "intelectuais de gabinete". Mário se permitia experienciar a cultura antes de jugá-la e tinha um projeto estético nacionalista que o permitiu encontrar valor na música popular, ao contrário de Adorno. Em particular, um elemento chama a atenção no discurso de Mário de Andrade: seu elevado senso de auto-crítica. Ele coloca: "Nós, os modernos, manifestamos dois defeitos grandes: bastante ignorância e leviandade sistematizada." (ANDRADE, 1972, p. 1) É justamente contra essa ignorância e leviandade que Mário se abre para cultura popular, observando manifestações musicais e sociais tanto no carnaval quanto em terreiros de macumba (TONI, 2004, p. 27), por exemplo, em que estariam presentes elementos da brasilidade perseguida pelo escritor paulistano.

Um forte ponto de contato entre os textos de Adorno e de Mário é que ambos podem ser entendidos como uma poética em seu sentido mais clássico. Desde Aristóteles, as poéticas configuram um espaço para elaboração de diretrizes estéticas que dizem aos artistas o que devem ou não fazer. Nesse sentido, o "Ensaio sobre a música brasileira" constitui uma poética que sugere, inspira e até mesmo propõe soluções práticas para os compositores em atividade. Já o texto "Sobre música popular" aparece como uma poética negativa que enfatiza não só aquilo que não deve ser feito em música, mas também aquilo que não deveria ser consumido enquanto produto. Claramente, as diretrizes poéticas dos dois intelectuais advêm de um interesse sócio-político que está além do material musical propriamente dito. Tal interesse é, em Mário, a afirmação de uma estética musical que valorize as bases culturais da formação social brasileira; em Adorno, a luta contra a massificação mercadológica dos objetos artísticos enquanto forma de resistência aos processos de reificação e alienação capitalista.

\subsection{Técnicas}

Se a técnica é o modo como se coleta, analisa e interpreta o material musical em questão, nisso se diferem bastante Mário e Adorno. Como colocado anteriormente, Mário de Andrade praticou muitas coletas de campo e, no cargo de Diretor de Cultura em São Paulo, promoveu expedições para diversos lugares do Brasil em busca de manifestações musicais populares (TONI, 2004). Nessas expedições, um grupo equipado com fonógrafo e máquina de "filmes sonoros" deveria capturar tais manifestações para transformá-las em "bem da cultura imaterial" (TONI, 2004, p. 45). Essa forma de captura cultural seria o passo seguinte àquele apresentado no "Ensaio sobre a música brasileira", em que as transcrições sonoras eram feitas de ouvido, no local mesmo da performance, pelo próprio Mário. Com o material gravado em mãos, seria ainda mais fácil levar adiante o projeto poético de apropriação da cultura popular para sua transformação, por parte dos artistas capacitados, em música artística brasileira.

Adorno, por sua vez, analisa a música popular a partir da difusão de produtos 
da Tin Pan Alley, alameda que ficou famosa nos EUA dos anos 1940 por ser o "reduto dos produtores de hits calcados no jazz" (ADORNO, 1986, p. 120). Os hits, para Adorno, são o cerne do que deveria ser excluído da produção musical devido ao seu alto grau de padronização - ou "estandardização", termo de que falaremos mais adiante. O auge de tal padronização se materializa nos manuais de "como produzir um hit", popularizados justamente nessa época de explosão da indústria fonográfica. No texto "Sobre música popular", em nenhum momento é utilizada a análise de partitura como procedimento de investigação. Isso porque, para Adorno, o grande problema com a música popular não está na sua falta de complexidade ou pobreza de parâmetros musicais, mas sim no uso de artifícios estéticos, por parte dos produtores, que escamoteiam a eterna repetição de estruturas musicais para apresentar um produto superficialmente renovado que possa ser consumido repetidas vezes. Assim, ele descreve a lógica do glamour que aparece em orquestrações e arranjos extravagantes; da fala de criança que propositadamente "erra" para fazer graça; e do emprego de timbres "adocicados" que embalam o hit como se fosse um bombom (ADORNO, 1986, p. 127-128). Todos esses seriam truques empregados na produção de um objeto de consumo que inibe o senso crítico do ouvinte.

O que fica claro neste ponto é que o foco da análise musical de Adorno não é o material sonoro propriamente dito; antes, a estrutura musical dos hits serve como embasamento para uma teoria estética social que busca denunciar a lógica de mercantilização da música que, para o filósofo alemão, só pode ser combatida com a vanguarda radical e progressista personificada na figura de Schoenberg e sua escola atonal2.

A concepção de música popular apresentada por Mário e por Adorno parece se distanciar em termos práticos. Talvez possa-se dizer que Mário está mais interessado em uma música folclórica, do povo, e que ainda não está registrada em material fonográfico, enquanto Adorno justamente está apontando para a apropriação capitalista dessa música que surgiu do povo mas não mais o pertence. Entretanto, o ponto de contato entre os dois intelectuais permanece: é o da predileção pelo que denominam música artística, séria, que tem sua origem na tradição europeia ${ }^{3}$. Assim, nas suas respectivas concepções, o projeto estético de Mário propõe uma incorporação da música popular associada à música artística para a consolidação de uma arte nacional e moderna; Adorno, por sua vez, propõe uma ruptura completa com a tradição tonal que se vê assimilada pelo capitalismo, encontrando para tanto a única possibilidade na vanguarda musical europeia atonal.

\subsection{Método}

Neste trecho em que abordaremos o método adotado pelos intelectuais verificaremos as concepções de arte que norteiam seus discursos e, por consequência,

\footnotetext{
20 próprio título do primeiro capítulo de Philosophy of new music expõe essa predileção: "Schoenberg and progress" carateriza o compositor alemão como progressista, enquanto Stravinsky, o neo-clássico de linguagem tonal, nos é apresentado como conservador, restaurador, no capítulo "Stravinsky and restoration" (ADORNO, s/d)
}

3 "Se um artista brasileiro sente em si a força do gênio, que nem Beethoven e Dante sentiram, está claro que deve fazer música nacional. Porque como gênio saberá fatalmente encontrar os elementos essenciais da nacionalidade (Rameau Weber Wagner Mussorgski)" (ANDRADE, 1972, p. 4) 
manifestam suas ideologias. Tanto Mário quanto Adorno aceitam de antemão a divisão binária entre música popular e música artística, ou música séria, como Adorno prefere chamá-la. Mário, em certo ponto do Ensaio, se propõe a problematizar o que se entende por música popular, mas apenas para ampliar seu olhar sobre o conceito e não para aproximá-la da música artística. Assim, nenhum dos dois questiona a legitimidade de tal oposição, sendo que ambos têm claramente a música clássica europeia como representante máxima da tradição musical artística. Mário coloca que "a música artística não é fenômeno popular mas desenvolvimento deste" (ANDRADE, 1972, p. 12), frase em que fica atestada a oposição binária entre música popular e música séria e que implica numa certa noção de progresso, em que um estágio inicial se desenvolve para um estágio avançado. A posição de Adorno, diferente da de Mário, coloca os dois pólos como estritamente separados, e não coloca a apropriação da música popular como uma possibilidade para a música séria. Logo no início do seu texto "Sobre música popular", Adorno expõe sua distinção entre as "duas esferas da música", sendo que a música popular opõe-se à música séria por sua característica fundamental de "estandardização". (ADORNO, 1986, p. 116)

A afirmação de Mário de Andrade sobre a música artística enquanto desenvolvimento do fenômeno popular pode ainda ser análoga à noção de detalhe musical fornecida por Adorno. O detalhe musical, segundo o filósofo alemão, está presente nas obras tanto de Beethoven quanto de Schoenberg e pode ser entendido como a célula mínima de uma composição musical que, sendo desdobrada pelo compositor, gera naturalmente o material sonoro como se fosse um organismo ${ }^{4}$. 0 detalhe seria então a base de toda uma peça, que dele derivaria pelas mãos do gênio. Justamente, à noção de organicismo foi atribuído um julgamento de valor positivo na história da música ocidental, como se vê em Adorno que afirma: "Um detalhe musical impedido de desenvolver-se torna-se uma caricatura de suas próprias potencialidades" (ADORNO, 1986, p. 119). Ou seja, aquela música que repete distraidamente suas estruturas estaria ignorando o detalhe. Retomando a afirmação de Mário de Andrade, quando ele diz que a música artística deve desenvolver-se do fenômeno popular fica implícita uma leitura em que a música popular se constitui por uma sucessão de detalhes, fragmentos que, no projeto poético de Mário, devem ser selecionados pelo compositor e desenvolvidos artisticamente em todas as suas potencialidades: "O artista tem só que dar para os elementos já existentes uma transposição erudita que faça da música popular, música artística" (ANDRADE, 1972, p. 16) Neste ponto, há uma diferença importante entre a poética de Mário e a de Adorno: a de Mário coloca a arte a serviço da construção da identidade nacional; a de Adorno, tem a arte experimental como único meio de resistência aos processos de dessubjetivação do capitalismo. O primeiro coloca a subjetividade artística excessiva como um empecilho para a obra nacionalista, que deve ter origem na música popular; o segundo coloca a subjetividade artística exacerbada como arte de vanguarda, totalmente oposta à música popular massifica-

\footnotetext{
4 Na música popular "O todo é preestabelecido e previamente aceito, antes mesmo de começar a real experiência musical [...] Em momento algum qualquer ênfase é colocada sobre o todo como um evento musical, nem tampouco a estrutura do todo depende dos detalhes.". Na música séria "cada detalhe deriva o seu sentido musical da totalidade concreta da peça, que, em troca,
}

consiste na viva relação entre os detalhes, mas nunca na mera imposição de um esquema musical" (ADORNO, 1986, p. 117) 
da.

Ao descrever a condição deste indivíduo dessubjetivado pela arte massificada, mas que cegamente continua consumindo os mesmos produtos, Adorno mobiliza o conceito de pseudo-individuação, em que o indivíduo acredita estar tomando decisões de acordo com o seu gosto mas na verdade está escolhendo entre produtos padronizados ${ }^{5}$. Richard Middleton nos ajuda a esclarecer o conceito:

Porque as pessoas gostam de pensar que cultura é diferente de outros produtos comercializados (a 'arte' incorpora expressão individual), formas e métodos estandardizados são mascarados em certa medida pela apresentação de uma habilidade artesanal e por efeitos 'pseudo-individualizados'. ${ }^{6}$

Adorno aponta justamente para a ideologia do "gosto musical" operada pela indústria fonográfica com a separação e comércio dos gêneros musicais, diante dos quais o indivíduo acredita exercer seu gosto individual e ser senhor de suas decisões, mas essencialmente opta entre um ou outro produto pré-selecionado ${ }^{7}$. Assim, para combater a pseudo-individuação, a música séria deverá romper radicalmente com a tradição musical para atingir a percepção do ouvinte na forma de um choque, de um estranhamento. É necessário ir contra a massificação do entretenimento afirmando radicalmente a subjetividade por meio de composições musicais que neguem os gêneros e os gostos musicais mercantilizados. Porém, a consequência fatal de tal atitude é o "isolamento social e deliberada incompreensão." (Idem, 1995, p. 36)

Mário de Andrade, embora também adepto da dita "música artística", estava mais preocupado com a afirmação da identidade nacional brasileira do que com a resistência ao capitalismo, o que é uma questão de caráter coletivo que se opõe ao individualismo adorniano. Com o "Ensaio sobre a música brasileira", ele buscou esclarecer compositores das possibilidades estéticas que deveriam ser levadas adiante naquele determinado momento histórico para que a produção artística pudesse contribuir com a formação dessa identidade. Uma das motivações para a escrita do ensaio é sua constatação de que "os artistas duma raça indecisa se tornaram indecisos que nem ela". (ANDRADE, 1972, p. 1) Assim, seus julgamentos acerca do que considerava música boa ou música ruim passam pelo crivo político do nacionalismo, que carrega consigo uma noção teleológica de progresso irreconciliável com a lógica da cultura popular, que se transforma constantemente mas não opera na esfera do progresso, já que não possui uma finalidade determinada.

A epígrafe de abertura do texto de Adorno em Philosophy of new music é uma citação de Hegel que concebe o fenômeno artístico como revelação de uma verdade $^{8}$. Mário de Andrade, nesse mesmo sentido, apresenta um projeto estético em busca dessa verdade, que para ele era a identidade brasileira, tão radical a ponto de

\footnotetext{
5 "Por pseudo-individuação entendemos o envolvimento da produção cultural de massa com a auréola da livre-escolha ou do mercado aberto, na base da própria estandardização." (Idem, p. 123)

6 "Because people like to think that culture is different from other commercially produced goods ('art' embodies individual expression), standardized methods and forms are masked to some extent by a show of artisan craftsmanship and by 'pseudo-individualized' effects" (MIDDLETON, 1995, p. 36) (Tradução do autor).
}

7 "Pode-se acrescentar que o reconhecido valor social inerente ao hit está envolvido na transferência da gratificação da propriedade para o objeto, que, assim, passa a ser 'gostado'. O processo de rotulação vem aqui coletivizar 0 processo de apropriação. $O$ ouvinte sente-se lisonjeado porque ele também tem o que todo mundo tem." (ADORNO, 1986, p. 134) 
afirmar que "Todo artista brasileiro que no momento atual fizer arte brasileira é um ser eficiente com valor humano. O que fizer arte internacional ou estrangeira, se não for gênio, é um inútil, um nulo. E é uma reverendíssima besta." (ANDRADE, 1972, p. 4). Inútil ou nulo porque não contribui para o progresso do projeto nacionalista de Mário de Andrade, que tinha esta como a única verdade digna da música artística brasileira na primeira metade do século XX.

\section{Modernismo e ideologia}

Além de um período mais ou menos historicamente delimitado, o Modernismo pode ser entendido como uma das grandes narrativas que guiaram os discursos culturais no ocidente dos últimos séculos. Beard \& Gloag definem uma grande narrativa como "modos ideologicamente determinados de perceber e estruturar sociedades e culturas", e colocam o modernismo como uma "grande narrativa, datada do período do Iluminismo, [que] pode ser vista como determinante para a crença Ocidental Europeia na necessidade de progresso do conhecimento, das artes, da tecnologia e da liberdade humana" 8

Mário de Andrade e Theodor Adorno podem ser associados à narrativa modernista não só por terem produzido durante o século XX pré-II Guerra Mundial, mas também porque claramente possuem em seus discursos traços racionalistas e progressistas. Tanto a projeção nacionalista de Mário, quanto a aposta de resistência ao capitalismo por parte da vanguarda em Adorno, são projetos que decorrem da crença em uma verdade fundamental, em um objetivo a ser alcançado que se situa num futuro para qual o progresso racional é o caminho. Este objetivo, para Mário, é a afirmação da identidade brasileira; para Adorno, a emancipação do sujeito da alienação capitalista. Ambos os projetos acabam se mostrando, fatalmente, utópicos, já que estão apoiados em parâmetros que pretendem ser universais e que reduzem a multiplicidade e complexidade de seu contexto social. Esses universais, como a imposição de um modelo estético enquanto solução revolucionária, ou a necessidade de uma afirmação identitária para consolidação de uma sociedade, carregam consigo ideologias que se tornam opressoras na medida em que negam radicalmente toda manifestação contrária ao progresso. Além disso, tendo em mente que tanto Mário quanto Adorno possuem modelos artísticos europeus como seus modelos de música artística, seus projetos, embora se proponham emancipadores, acabam por reproduzir disputas de poder características de uma postura conservadora e eurocêntrica.

\section{Conclusão}

Mário de Andrade e Theodor Adorno são ícones do pensamento estético de

8 "For in art we have to do not with any agreeable or useful child's play, but ... with an unfolding of the truth" (HEGEL, apud ADORNO, s/d, p. 7)
9 "Ideologically determined ways of perceiving and structuring societies and cultures"; "master narrative, which dates from the time of the Enlightenment, [that] can be seen to have determined a Western European belief in the need for progress in knowledge, in the arts, in technology and in human freedom." (BEARD; GLOAG, 2005, p. 86) (Tradução do autor) 
seu tempo. Ambos contribuíram muito para a filosofia e produção artística de sua sociedade, lançando também um debate musicológico que muito tem sido explorado nas últimas décadas: a questão da música popular, da música artística, suas possíveis distinções e tensões. Com discursos elaborados e muito esclarecidos do que almejavam construir, seus procedimentos e suas argumentações são esclarecedores de muitas questões que antes deles estiveram ocultas.

Mário de Andrade ajudou a pensar a configuração da sociedade brasileira, sua complexidade e suas disputas culturais que se manifestaram na música no momento do aparecimento da indústria fonográfica. Colaborou também para a reflexão acerca da produção artística em um país culturalmente colonizado e recém saído da escravidão. Theodor Adorno, por sua vez, apontou para os perigos da tecnologia industrial e sua apropriação das expressões subjetivas, tornando-as objetos de consumo, colocando a arte a serviço da consolidação capitalista. Com sua complexa teoria social estética, identificou um inimigo em potencial que permanecia oculto até aquele momento.

Ambos, porém, proferiram seus discursos sob a ideologia racional do modernismo, e portanto apresentam concepções de arte e cultura que atualmente se encontram em descrédito devido ao surgimento de teorias que questionam o paradigma de verdade apresentado pelo radicalismo modernista. A musicologia do século XXI deve muito às investigações desenvolvidas ao longo do século anterior. Entretanto, desde os questionamentos iniciados nos anos 1960 segue em busca de outros horizontes teóricos menos focados em discursos objetivos acerca da prática musical humana, já que

discursos modernistas sobre verdade, conhecimento, justiça e beleza são na verdade sobre poder político e controle, a convicção de que a razão fornece um aparato neutro, objetivo, possibilitando o acesso humano a verdades fundadoras ou absolutas não é mais sustentável... [O pós-modernismo] frequentemente assume um ceticismo vigorosamente desafiador em relação às narrativas modernistas... sendo sensível aos modos como tais estórias dissimuladamente serviram aos interesses do poder, do controle e da opressão. ${ }^{10}$

Ao investigarmos a forma como Adorno e Mário conduzem seus pilares de pesquisa, tal como definidos por Castagna, procedemos a tentativa de uma leitura crítica que justamente se embasa em uma certa desconfiança e ceticismo a respeito de discursos estéticos totalizadores que acabam se tornando totalitários. Assim, pudemos identificar os discursos modernistas sobre "poder político e controle" elaborados pelos autores e obtivemos esclarecimentos a respeito de como procedimentos de pesquisa se conectam e refletem a ideologia do pesquisador.

Acreditamos na importância de analisar criticamente discursos de intelectu-

\footnotetext{
10 "[modernist] discourses about truth, knowledge, justice, and beauty are really about political power and control, the conviction that reason provides the neutral, objective machinery enabling human access to foundational of absolute truths is no longer tenable... [Postmodernism] often assumes a strenuously defiant... skepticism toward modernist narratives... sensitivity to the ways such stories covertly served the interests of power, control and oppression." (BOWMAN, apud BEARD; GLOAG, 2005, p. 86) (Tradução do autor)
} 
ais do século XX para que possamos compreender fundamentos epistemológicos da musicologia enquanto campo de pesquisa. A busca por ressignificações da ideologia modernista, em particular, é enriquecedora se consideramos que, longe de estar superada, esta grande narrativa permanece latente e em tensão com suas leituras críticas mais atuais. Tal busca permanece, então, como uma possibilidade de estudo a ser desenvolvido em novas pesquisas que estejam dispostas a se debruçar sobre discursos, paradigmas e ideologias de maneira crítica, o que contribuirá continuamente para maior produtividade na área da musicologia. 


\section{Referências:}

ADORNO, Theodor. O fetichismo na música e a regressão da audição. Nova Cultura, São Paulo: 1996.

Minneapolis: s/d.

Philosophy of new music. University of Minnesota Press, Sobre música popular. In: COHN, Gabriel (org.). Coleção grandes cientistas sociais. Ática, São Paulo: 1986.

ANDRADE, Mário. Ensaio sobre a música brasileira. 3a ed. São Paulo: Vila Rica; Brasília: INL, 1972.

BEARD, David; GLOAG, Kenneth. Modernism. In: Musicology: key concepts. Routledge, New York: 2005.

CASTAGNA, Paulo. A musicologia enquanto método científico. In: Revista do conservatório de música UFPel nำ1. 2008.

disponível em: <http://www.ufpel.edu.br/conservatorio/revista/revista.html>

MIDDLETON, Richard. 'It's all over now'. Popular music and mass culture Adorno's theory. In: Studying popular music. Open University Press, Ballmor: 1995.

TONI, Flávia Camargo. Eu victrolo, tu victrolas, ele victrola. In: A música popular na vitrola de Mário de Andrade. Ed. Senac, São Paulo: 2004. 